\title{
The nanostructure of barium dititanate prepared by hydrothermal method
}

\author{
Sarah L. Rasheed and Emad K. Al-Shakarchi* \\ Physics Department, College of Science \\ Al-Nahrain University, Baghdad, Iraq \\ *eks2000@ hotmail.com
}

Received 10 November 2018; Revised 27 February 2019; Accepted 27 February 2019; Published 22 March 2019

\begin{abstract}
The dielectric ceramic of barium dititanate compound $\mathrm{BaTi}_{2} \mathrm{O}_{5}$ had been prepared through the hydrothermal process by applying different parameters, such as $\mathrm{pH}$-value, reaction time, temperature and pressure. The prepared powders were examined by $\mathrm{X}$-ray diffraction (XRD). The predominant phase was a monoclinic phase with lattice constants ( $a=16.6381, b=3.555, c=9.3406 \AA$ ), $\left(\beta=107.47^{\circ}, \alpha=\gamma=90^{\circ}\right)$, and the unit cell volume $\left(527 \AA^{3}\right)$. The surface morphology was demonstrated by Scanning Electron Microscopy (SEM). It exhibited the grains in spherical and elliptical shapes with high homogeneity. The shapes of nanostructure were analyzed by Transmission Electron Microscopy (TEM). The appearance of nanostructures like the nanoparticles and nano rods were found. The size of nanoparticles was in the range of 9-31 nm, and size of nanorods was $32-37 \mathrm{~nm}$. The dielectric measurements were done by using LCR meter at different temperature and frequencies $(10,50$ and $100 \mathrm{kHz})$. It was clear that the Curie temperature had a high value up to $\left(485^{\circ} \mathrm{C}\right)$. The relative permittivity was partially changed for two prepared samples regarding high pressure and long reaction time, which were the main preparation conditions of hydrothermal method.
\end{abstract}

Keywords: Barium dititanate; hydrothermal method; nanostructures; monoclinic phase; dielectric properties.

\section{Introduction}

This research is a complement to the previous one dealing with $\mathrm{BaTiO}_{3}$ ferroelectric material. ${ }^{1-3}$ The high dielectric constant of $\mathrm{BaTiO}_{3}$ and its environmentally friendly $\mathrm{Ba}-\mathrm{Ti}-\mathrm{O}$ family make them more compatible in industrial applications. The $\mathrm{BaO}-\mathrm{TiO}_{2}$ system is considered as the base of ferroelectric ceramic materials. It showed a cubic perovskite structure or hexagonal structure useful in many applications in electrical devices. ${ }^{4-7}$ Many researches discussed the phase diagram of $\mathrm{BaO}-\mathrm{TiO}_{2}$, which possesses several high quality dielectric and ferroelectric properties such as $\mathrm{BaTiO}_{3}$, $\mathrm{BaTi}_{2} \mathrm{O}_{5}, \mathrm{Ba}_{6} \mathrm{Ti}_{17} \mathrm{O}_{40}, \mathrm{Ba}_{4} \mathrm{Ti}_{13} \mathrm{O}_{30}, \mathrm{Ba}_{2} \mathrm{Ti}_{9} \mathrm{O}_{20}, \mathrm{BaTi}_{4} \mathrm{O}_{9}$ and $\mathrm{BaTi}_{5} \mathrm{O}_{11} \cdot{ }^{8}$ The new ferroelectric material was $\mathrm{BaTi}_{2} \mathrm{O}_{5}$, it had a monoclinic phase and high Curie temperature reaching $748 \mathrm{~K}$. It had a high permittivity $(\varepsilon=20500)$ along the $b$-axis plane at $748 \mathrm{~K}$. This value was greater than that of $\mathrm{BaTiO}_{3}$ $(\varepsilon=7600)$ at $400 \mathrm{~K}$ and $\mathrm{Bi}_{4} \mathrm{Ti}_{3} \mathrm{O}_{12}(\varepsilon=600)$ at $940 \mathrm{~K}$. The permittivities of $\mathrm{BaTi}_{2} \mathrm{O}_{5}$ were about (140 and 70) along $a$-axis and $c$-axis, respectively, independent of temperature. ${ }^{8}$

The $\mathrm{BaTi}_{2} \mathrm{O}_{5}$ is a promising material in many applications in comparison with $\mathrm{PbTiO}_{3}$ because of high Curie temperature. The preparation of single crystal $\mathrm{BaTi}_{2} \mathrm{O}_{5}$ powder by conventional solid state method is very difficult due to decomposition into $\mathrm{Ba}_{6} \mathrm{Ti}_{17} \mathrm{O}_{40}$ and $\mathrm{BaTiO}_{3}$ at about $1423 \mathrm{~K}$. Many techniques had been utilized to prepare a pure phase of $\mathrm{BaTi}_{2} \mathrm{O}_{5}$ compound, such as sol-gel method, ${ }^{10-16}$ hydrothermal reaction, ${ }^{9-11}$ containerless processing, ${ }^{12-15}$ arc melting, ${ }^{13}$ and Spark Plasma Sintering (SPS). ${ }^{14}$ The most efficient is the hydrothermal process, due to many reasons represented by the simplicity applicable in the laboratory. It needs a long reaction time with a reasonable temperature, as was mentioned before. ${ }^{17}$ The possible advantages of hydrothermal method over other types of crystal growth include the ability to create the crystalline phases, which are unstable at melting point. The materials have a high vapor pressure near their melting point that can be grown by the hydrothermal method. ${ }^{18}$ This is a reason why it was used in this research. There is a probability to produce a single phase and different nanostructures of $\mathrm{BaTi}_{2} \mathrm{O}_{5}$ by changing the preparation parameters. A feature of this method is it needs a long reaction time and high temperature applied on the autoclave to create the nanostructures and produce the single phase of $\mathrm{BaTi}_{2} \mathrm{O}_{5}$, whereas they were difficult to obtain through the conventional solid-state reaction through the low cooling rate in the thermal process. ${ }^{14}$

The main parameters of dielectric material are the relative permittivity $\left(\varepsilon_{r}\right)$ and the loss tangent $(D)$. The relative permittivity is the ratio of absolute permittivity $(\varepsilon)$ to the space permittivity $\left(\varepsilon_{o}\right)$. The real part of permittivity $\left(\varepsilon^{\prime}\right)$ is a measure of how much energy from an external electric field is stored inside the material. The imaginary part of permittivity $\left(\varepsilon^{\prime \prime}\right)$ is called the loss factor and is a measure of how much energy is lost in the material. The imaginary part of permittivity $\left(\varepsilon^{\prime \prime}\right)$ is always greater than zero and is usually much smaller than $\left(\varepsilon^{\prime}\right)$. The loss tangent $(D)$ is defined as the ratio of energy lost/cycled or imaginary part of the dielectric constant to the energy stored/cycled or real part, and it is a function of quality factor $(Q)$. The $Q$-factor is the inverse of

This is an Open Access article published by World Scientific Publishing Company. It is distributed under the terms of the Creative Commons Attribution 4.0 (CC-BY) License. Further distribution of this work is permitted, provided the original work is properly cited. 
loss tangent and it is used with respect to an electronic microwave device.

\section{Experimental Procedure}

The formation of $\mathrm{BaTi}_{2} \mathrm{O}_{5}$ phase was produced by mixing the starting materials, such as Barium Chloride Dihydrate $\left(2 \mathrm{M} \mathrm{BaCl}_{2} \cdot 2 \mathrm{H}_{2} \mathrm{O}\right)$ and Titanium Dioxide $\left(\mathrm{Ti}_{2} \mathrm{O}\right)$. The mixture is dissolved in distilled water, then an appropriate amount of Sodium Hydroxide solution $(\mathrm{NaOH})$ is added dropwise to the mixture in order to control the $\mathrm{pH}$ values in the range (8-10) separately. Later, the solution is placed in a Teflon flask $150 \mathrm{ml}$ inside a homemade autoclave. The autoclave had a size $200 \mathrm{ml}$, and is a sealed evacuated device that was heated to temperature range $\left(195-208^{\circ} \mathrm{C}\right)$ for $(24$ and $60 \mathrm{~h})$ under a pressure of about 15-20 bar, respectively. Then it had cooled down slowly to room temperature. The solution was washed five times by distilled water to separate the net mixture from salts and undesirable materials. The powder was dried in oven at $125^{\circ} \mathrm{C}$ for $5 \mathrm{~h}$, later the powder was ground and calcined at temperature $\left(700^{\circ} \mathrm{C}\right)$ for $6 \mathrm{~h}$. The calcination process was necessary to make a pure phase and the weight of the powder less than before. The obtainable white color powder characterized by X-ray diffraction (XRD, SHIMADZU-600, JAPAN) with $\mathrm{Cu}$ source $(\lambda=1.5406 \AA)$, the applied voltage $(40 \mathrm{kV})$ and current $(30 \mathrm{~mA})$. The shape and size of nanostructures of Barium Dititanate is characterized by Transmission Electron Microscopy (TEM, Zeiss, Libra 120 model) with accelerating voltage of $120 \mathrm{kV}$. The surface morphology and their results had been done by Scanning Electron Microscopy (SEM, TESCAN VEGA 3) with accelerating voltage of about $20 \mathrm{kV}$. The resultant powder compacted into pellets with a diameter of $1 \mathrm{~cm}$ by homemade stainless steel die and electrical press at pressure of $127 \mathrm{MPa}$. The produced pellet was sintered at $900^{\circ} \mathrm{C}$ for $12 \mathrm{~h}$, the pellet becomes denser. Finally, the coating of gold electrode on the surface of the pellet was applied for a dielectric measurements under vacuum by LCR-meter type (Wayne Kerr 6500 P).

\section{Results and Discussion}

The XRD analysis was a powerful technique to show the phase required by $\mathrm{BaTi}_{2} \mathrm{O}_{5}$ to calculate the lattice parameters and space group, for the sample prepared under the conditions $\mathrm{pH}=10$, pressure $=15$ bar, reaction temperature $=$ $195^{\circ} \mathrm{C}$ and reaction time $=24 \mathrm{~h}$, as shown in Fig. 1. The standard pattern was taken from Inorganic Crystal Structure Database (ICSD98-015-3286). The analysis of XRD pattern showed the presence of monoclinic phase of $\mathrm{BaTi}_{2} \mathrm{O}_{5}$ with (space group $\mathrm{C} 2 / \mathrm{m})$, unit-cell parameters $(a=16.6381$, $b=3.555, c=9.3406 \AA),\left(\beta=107.47^{\circ}, \alpha=\gamma=90^{\circ}\right)$, and the volume $\left(527 \AA^{3}\right)$. There is a difference in the lattice constants from the previous studies ${ }^{16,19}$ and agreement with others. ${ }^{14,20}$ This contradiction returns to the elongation of

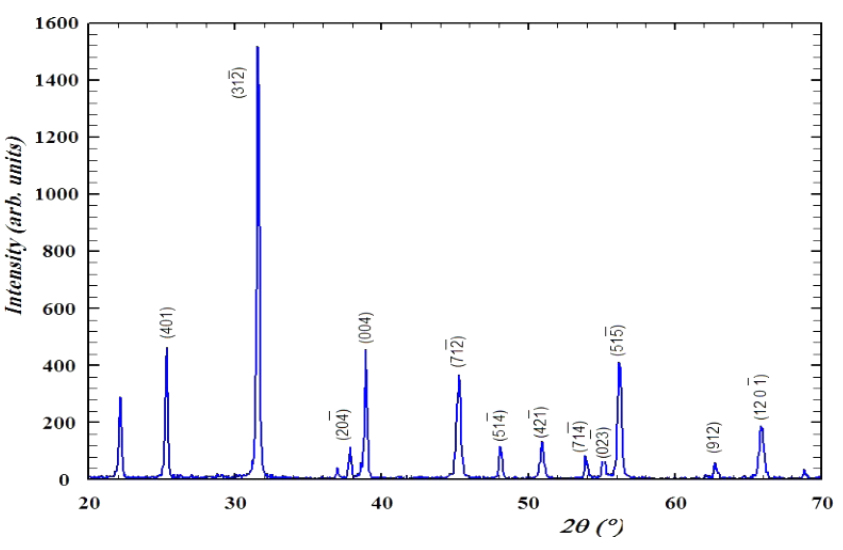

Fig. 1. XRD pattern of $\mathrm{BaTi}_{2} \mathrm{O}_{5}$ for the sample prepared at $\mathrm{pH}=$ 10 , pressure $=15$ bar, reaction temperature $=195^{\circ} \mathrm{C}$ and reaction time $=24 \mathrm{~h}$.

$a, c$-axes, and the obtuse angle had a direct effect on the torque of electric charge that goes to maximum value. This difference had been affecting the polarization strength through the torque value produced by $\beta$-angle. Both the peak positions and their intensities had been a direct effect on the stability of the phase required such that the shifting in the peaks tend to a limited change in the lattice constants, and the strain possibility in the lattice constants. The last one is affected by the polarization strength during the change in the bond length. On the other hand, the intensity of the peaks is a function to the concentration of these planes including the monoclinic unit cell. Then the change in the intensities with standard one was the key to drive the obtainable phase from the database (ICSD98-015-3286). There is only one unknown peak at $\left(2 \theta=22.2^{\circ}\right)$, appearing in the pattern mentioned by Fig. 1, which was related to such unreacting materials. In general, the preparation condition is very important to complete the chemical reaction inside the autoclave. It was clear that the main conditions concentrated on the pressure and reaction time. So, the high pressure and long reaction time was the way to complete the reaction as mentioned in the second sample represented by the vanishing of unknown peak, as shown in Fig. 3.

The peaks mentioned by XRD patterns were identical with standard one. They showed the presence of the monoclinic with difference in the lattice constants compared with reference data. That was returned to a slight shifting in the peak positions mentioned in XRD patterns. The main orientation of the monoclinic phase represented by the plane $(31 \overline{2})$ that is in contradiction with standard one, which was $(31 \overline{1})$. This is the reason why the $c$-axis is longer than the standard value. The shape of the crystal structure simulated by Crystaldrifact UNTITLED and Diamond software, as shown in Fig. 2. It was clear that the monoclinic unit cell was presented with $\beta=107.47^{\circ}$, and there were many octahedron structures per unit cell composed of $\mathrm{Ti}-\mathrm{O}$ atoms. So, the concentration of these octahedrons were a function of the strength of 


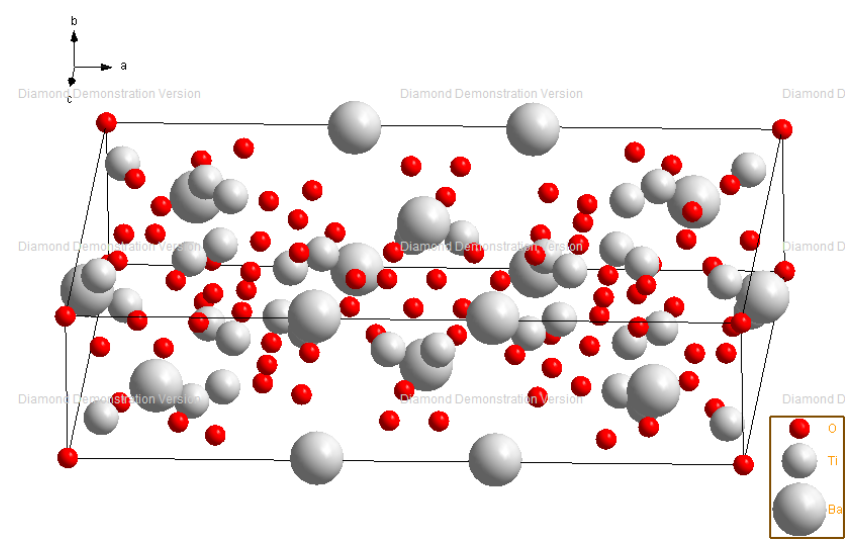

Fig. 2. The Crystal unit cell of $\mathrm{BaTi}_{2} \mathrm{O}_{5}$, the octahedron structure created from Ti-O atoms including.

ferroelectric included. There were three Ti-atoms with different position, and eight $\mathrm{O}$ atoms distributed in different sits inside the monoclinic, as mentioned in Table 1 . They were the principle to create the octahedron structures.

The XRD pattern of $\mathrm{BaTi}_{2} \mathrm{O}_{5}$ under the condition $\mathrm{pH}=8$, pressure $=20 \mathrm{bar}$, temperature $=208^{\circ} \mathrm{C}$ and the reaction time $=60 \mathrm{~h}$, was as shown in Fig. 3. The crystalline phase of $\mathrm{BaTi}_{2} \mathrm{O}_{5}$ was monoclinic phase with the unit-cell parameters $(a=16.9992, b=3.7764, c=9.4852 \AA)$ and $\left(\alpha=\gamma=90^{\circ}\right.$, $\left.\beta=102.947^{\circ}\right)$. There is a limited variation in the lattice constants and limited reduction in the polarization angle $(\beta)$ compared with last one, which returned to preparation conditions. Since the location of the strong peak (401) mentioned at $2 \theta=25.44^{\circ}$ was similar to the standard value (ICSD98015-3286), all the diffracted peaks had low intensity in comparison with the previous one. The featured thing was no undefined peak that means the long reaction time and high pressure was suitable to complete the reaction inside autoclave and producing a pure phase of $\mathrm{BaTi}_{2} \mathrm{O}_{5}$. The creation of pure phase is regarding appearance of the all peaks mentioned

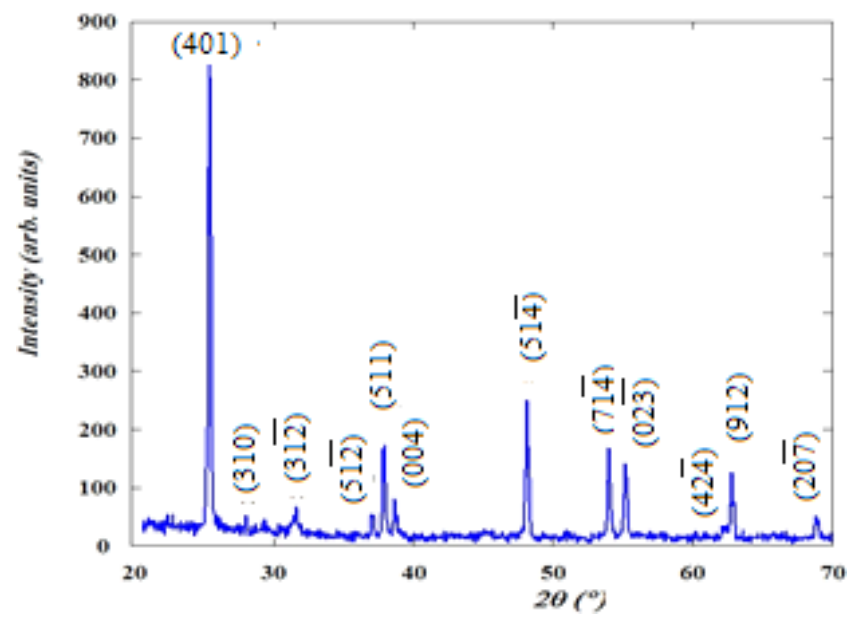

Fig. 3. XRD pattern of $\mathrm{BaTi}_{2} \mathrm{O}_{5}$, under $\mathrm{pH}=8$, pressure $=20$ bar, temperature $=208^{\circ} \mathrm{C}$ and the reaction time $=60 \mathrm{~h}$.
Table 1. The position of atoms inside the unit cell for $\mathrm{BaTi}_{2} \mathrm{O}_{5}$ prepared at $\mathrm{pH}=10$, pressure $=15 \mathrm{bar}$, temperature $=195^{\circ} \mathrm{C}$ and reaction time $=24 \mathrm{~h}$.

\begin{tabular}{llll}
\hline Atom & \multicolumn{1}{c}{$x / a$} & $y / b$ & \multicolumn{1}{c}{$z / c$} \\
\hline Ba1 & 0 & 0.5 & 0.5 \\
Ba2 & 0.36800 & 0 & 0.01240 \\
Ti1 & 0.16510 & 0 & 0.69930 \\
Ti2 & 0.20660 & 0 & 0.37450 \\
Ti3 & 0.03670 & 0 & 0.21050 \\
O1 & 0.78920 & 0 & 0.12480 \\
O2 & 0.10690 & 0 & 0.42840 \\
O3 & 0.05970 & 0 & 0.71190 \\
O4 & 0 & 0 & 0 \\
O5 & 0.15200 & 0 & 0.18990 \\
O6 & 0.53660 & 0 & 0.20880 \\
O7 & 0.26450 & 0 & 0.60400 \\
O8 & 0.32540 & 0 & 0.33890 \\
\hline
\end{tabular}

by Fig. 3 in comparison with ICSD98-015-3286. In addition to that, the disappearing of unknown peaks give more details on the stability of the phase $\mathrm{BaTi}_{2} \mathrm{O}_{5}$ nor the perovskite phase of $\mathrm{BaTiO}_{3}$. The simulation results by Diamond software emphasized the presence of $\mathrm{BaTi}_{2} \mathrm{O}_{5}$ as pure phase during the number of atoms included and their sites. The position of atoms were simulated as shown in Table 2, thus it was clear that there are many octahedron structures within the unit cell as mentioned Fig. 2.

In general the low intensity of diffracted peaks was the reason to prove the nanostructure in comparison with last one. The low intensity means the low half width of the peaks required in the measuring by Williamson-Hall equation. ${ }^{1,2}$ That was tend to presence more nanostructures in different shape through the long reaction time and high pressure. Already the phase stability and the limited change in the lattice constants was applied for both samples. Secondly, the orientation of the unit cell might be change and the direction

Table 2. The position of atoms inside the unit cell for $\mathrm{BaTi}_{2} \mathrm{O}_{5}$ prepared at $\mathrm{pH}=8$, pressure $=20 \mathrm{bar}$, temperature $=208^{\circ} \mathrm{C}$ and the reaction time $=60 \mathrm{~h}$.

\begin{tabular}{llll}
\hline Atom & \multicolumn{1}{c}{$x / a$} & $y / b$ & \multicolumn{1}{c}{$z / c$} \\
\hline Ba1 & 0 & 0.5 & 0.5 \\
Ba2 & 0.36800 & 0 & 0.01240 \\
Ti1 & 0.16510 & 0 & 0.69930 \\
Ti2 & 0.20660 & 0 & 0.37450 \\
Ti3 & 0.03670 & 0 & 0.21050 \\
O1 & 0.78920 & 0 & 0.12480 \\
O2 & 0.10690 & 0 & 0.42840 \\
O3 & 0.05970 & 0 & 0.71190 \\
O4 & 0 & 0 & 0 \\
O5 & 0.15200 & 0 & 0.18990 \\
O6 & 0.53660 & 0 & 0.20880 \\
O7 & 0.26450 & 0 & 0.60400 \\
O8 & 0.32540 & 0 & 0.33890 \\
\hline
\end{tabular}




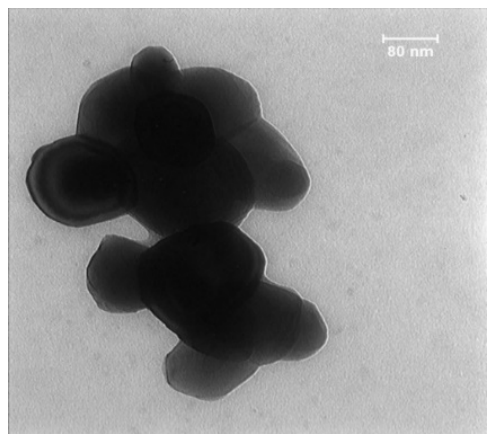

(a)

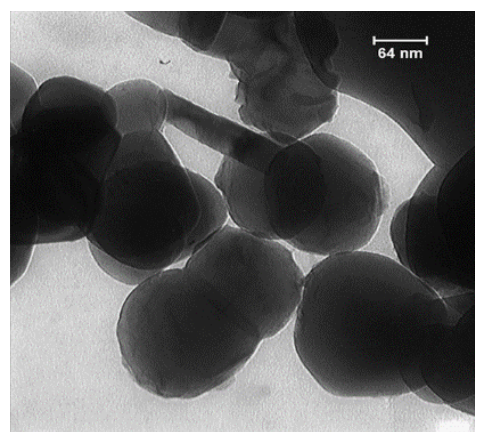

(b)

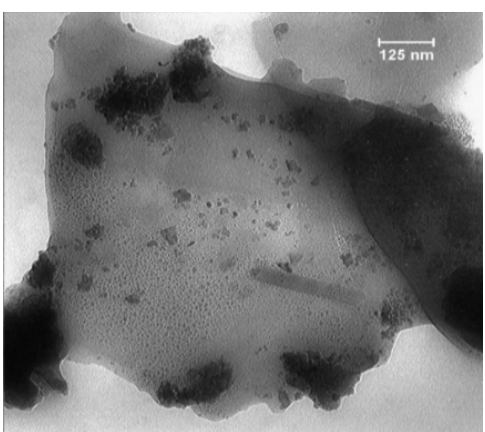

(c)

Fig. 4. (a) TEM micrograph of $\mathrm{BaTi}_{2} \mathrm{O}_{5}$ powder, the magnification power $25,000 \mathrm{x}$, for the sample prepared at $\mathrm{pH}=10$, pressure $=15$ bar, reaction temperature $=195^{\circ} \mathrm{C}$ and reaction time $=24 \mathrm{~h}$. (b), (c) TEM micrograph of $\mathrm{BaTi}_{2} \mathrm{O}_{5}$ powder, the magnification power $16,000 \mathrm{x}$, for the condition $\mathrm{pH}=8$, pressure $=20$ bar, temperature $=208^{\circ} \mathrm{C}$ and the reaction time $=60 \mathrm{~h}$.

of the net polarization is depending on the obtuse angle represented by $(\beta)$ similar to standard data. The change in $\beta$-angle has a direct effect on the polarization direction within the unit cell, because the net of polarization is depending on the resultant torque that is producing from the bond $\mathrm{O}-\mathrm{Ti}-\mathrm{O}$ in the octahedron structure. That was cleared in the results of dielectric measurements.

The TEM images were necessary to show the presence of nanostructures and calculate the size of nanostructures. The analytical results, as shown in Fig. 4(a), for the first condition have a spherical shape with some agglomeration and the size of these particles are in the range (57-189 nm) in diameter. The second TEM images, as shown in Figs. 4(b) and 4(c), also reveal a partial agglomeration with nanoparticles size in the range of $9-31 \mathrm{~nm}$ as mentioned on Fig. 4(c), and appearing nanorode in size of $(32-37 \mathrm{~nm})$, as shown in Figs. 4(b) and 4(c), whereas the nanoparticle on the other region showed the size in the range $(73-181 \mathrm{~nm})$, as appearing in Fig. 4(b). As observed, a nanorode of $\mathrm{BaTi}_{2} \mathrm{O}_{5}$ nanostructures was obtained due to the ion-exchange interaction between sodium titanate nanorode and $\mathrm{BaCl}_{2}$. The comparison between the TEM pictures deal with the appearance of separated nanoparticles and nanorode rather than the first sample that showed agglomeration of nanoparticles. This agglomeration is justified because the ferroelectric behavior is affected by the electron beam of TEM-sources. The last is the reason to polarize the ferroelectric particle of $\mathrm{BaTi}_{2} \mathrm{O}_{5}$ and produce the agglomeration or partial agglomeration as shown in Figs. 4(a) and 4(b). These results showed that the long reaction time and high pressure are suitable to create reasonable nanostructure from the other one.

The surface morphology of the first product characterized by SEM analysis, is shown in Fig. 5(a). It showed the surface and cross-section of the $\mathrm{BaTi}_{2} \mathrm{O}_{5}$ powder prepared by a certain condition. It had a spherical and elliptical shape of grains with high homogeneity and average grain size was 55$321 \mathrm{~nm}$, there was a greater ratio of grains in the scale of $1 \mu \mathrm{m}$. The other sample had average grain size of 39-264 nm as shown in Fig. 5(b). The results of nanograins emphasized the presence of nanoparticle or nanorode mentioned in the

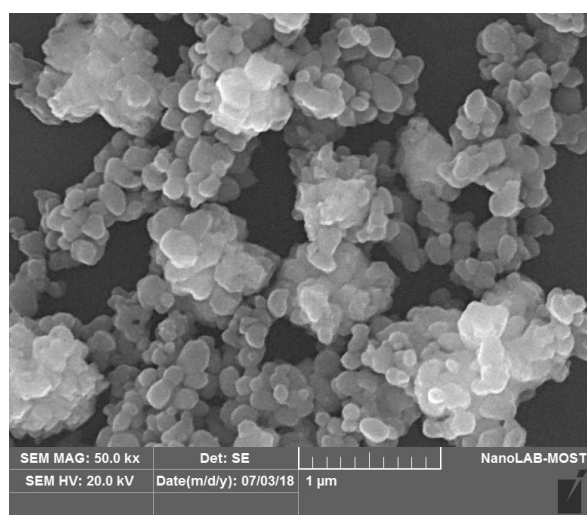

(a)

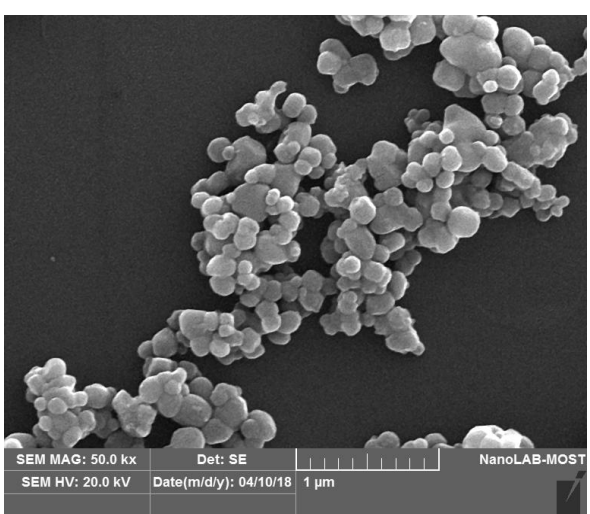

(b)

Fig. 5. (a) SEM micrograph of $\mathrm{BaTi}_{2} \mathrm{O}_{5}$ powder for the sample prepared at $\mathrm{pH}=10$, pressure $=15$ bar, reaction temperature $=195^{\circ} \mathrm{C}$ and reaction time $=24 \mathrm{~h}$. (b) $\mathrm{SEM}$ micrograph of $\mathrm{BaTi}_{2} \mathrm{O}_{5}$ powder for the condition $\mathrm{pH}=8$, pressure $=20$ bar, temperature $=208^{\circ} \mathrm{C}$ and the reaction time $=60 \mathrm{~h}$. 


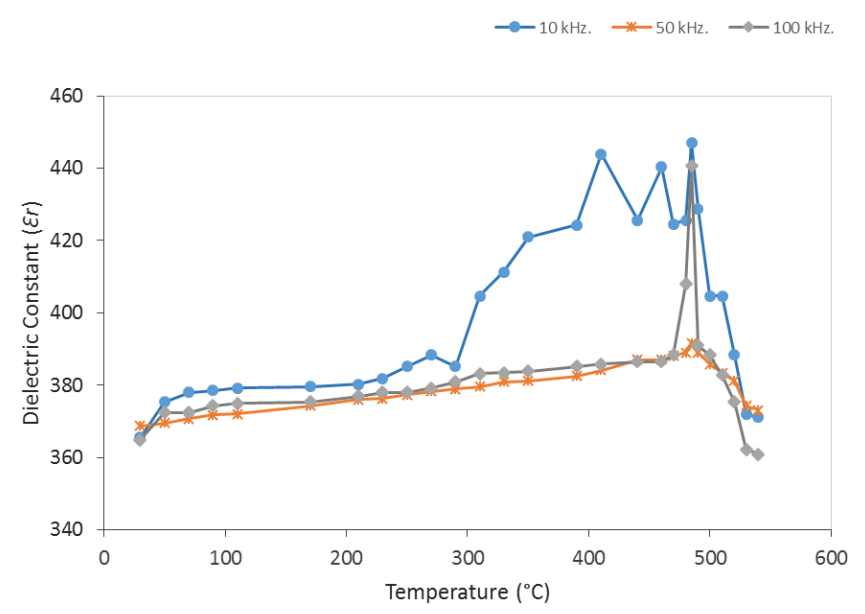

(a)

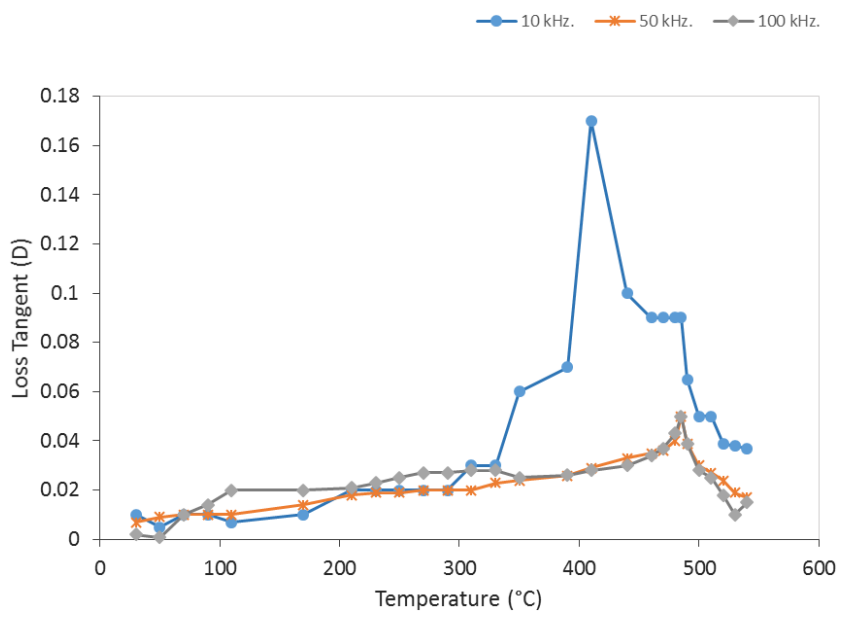

(b)

Fig. 6. The dielectric measurement of $\mathrm{BaTi}_{2} \mathrm{O}_{5}$ ceramics for the sample prepared at $\mathrm{pH}=10$, pressure $=15$ bar, reaction temperature $=195^{\circ} \mathrm{C}$, reaction time $=24 \mathrm{~h}$, and different frequencies, (a) dielectric constants, (b) loss tangent.

previous TEM analysis, because the nanostructures were already included within the grain. The thing mentioned in SEM analysis is return to high homogeneity of grains included. That is regarding the preparation method used, which was efficient under high pressure and long reaction time.

The dielectric measurement as a function of temperature and frequency had been done for the pellet sintered at $900^{\circ} \mathrm{C}$ for $12 \mathrm{~h}$. It was used to demonstrate the phase transition from ferroelectric to paraelectric at a certain Curie point, dielectric constant and loss tangent. The low sintering temperature was a proof of the presence of nanostructure, it conflicted with previous studies having high sintering temperature. ${ }^{21,22}$ The dielectric properties of $\mathrm{BaTi}_{2} \mathrm{O}_{5}$ ceramics for the sample prepared at $\mathrm{pH}=10$, pressure $=15$ bar, reaction temperature $=195^{\circ} \mathrm{C}$ and reaction time $=24 \mathrm{~h}$. It was measured as a function of temperature and different frequencies $(10,50$ and $100 \mathrm{kHz})$, as shown in Figs. 6(a) and $6(\mathrm{~b})$. The value of relative permittivity increases with increasing applied temperature, until it reaches maximum value at $\left(T_{c}=485^{\circ} \mathrm{C}\right)$. Then the relative permittivity decreases in a paraelectric state until the temperature $\left(540^{\circ} \mathrm{C}\right)$ that was returning to diminish the concentration of electric dipole moments and polarization in the structure.

It is well known that the Curie temperature is the maximum peak position of temperature and amount of thermal energy required to destroy the dipole moments, and the polarization. It goes to random distribution of electric dipole moments such that the net of polarization goes to zero. The above Curie point for three frequencies have the same value, which means there is no effect of frequency on the transform to paraelectric phase. That is, return to nanoparticles appeared with the similar size, such that the frequency has a unique effect on the nanoparticles and then on the octahedrons included. The temperature peak emphasized the strength of the polarizability and then the electric dipole moments represented by the permittivity. The critical temperature of $\mathrm{BaTi}_{2} \mathrm{O}_{5}$ crystals is grown from Ti-rich solution as emphasized previously. ${ }^{21}$ The relative permittivity values at Curie point $\left(485^{\circ} \mathrm{C}\right)$ equal to 447,391 and 440 for frequencies 10 , 50 and $100 \mathrm{kHz}$, respectively, are shown in Fig. 6(a). There is no sharp variation because the relative permittivity is produced by symmetrical nanoparticles applied and they are related to same octahedrons included in the structure, which have a partial change in the unit cell. The dielectric loss tangent goes to its minimum value of about 0.05 at the same Curie temperature at two frequencies $(50$ and $100 \mathrm{kHz})$ but it was 0.17 at $T_{c}=370^{\circ} \mathrm{C}$ for the frequency $(10 \mathrm{kHz})$, which is three times of above two frequencies, as mentioned in Fig. 6(b). Basically, the loss tangent is the ratio of reactive part of dielectric constant to real part of dielectric constant. On the other hand, the $Q$-factor is 20 and 5.88, respectively, which means the material is more effective at frequencies 50 and $100 \mathrm{kHz}$. The material has the ability to store much more energy rather than the lost one.

While the second sample of $\mathrm{BaTi}_{2} \mathrm{O}_{5}$ ceramic prepared by the condition $\mathrm{pH}=8$, pressure $=20$ bar, temperature $=$ $208^{\circ} \mathrm{C}$ and the reaction time $=60 \mathrm{~h}$, is indicated in Figs. 7(a) and 7 (b). The Curie point is equal to $485^{\circ} \mathrm{C}$ for all dependent frequencies, and the same for the previous one. Normally, the critical temperature is dependent on the chemical structure of the mixture and not on the preparation conditions, which is the reason why unique critical temperature appears. On the other hand, the Curie temperature is a function to the phase stability produced. That is relating to the degree of crystallinity or due to structural changes. The relative permittivity values at Curie point $\left(485^{\circ} \mathrm{C}\right)$ are equal to 963,743 and 708 at frequencies 10,50 and $100 \mathrm{kHz}$ as shown in Fig. 7(a), respectively. There is a sharp decrease in relative permittivity with frequency increase, and increase in permittivity compared with previous one because of different nanostructures 


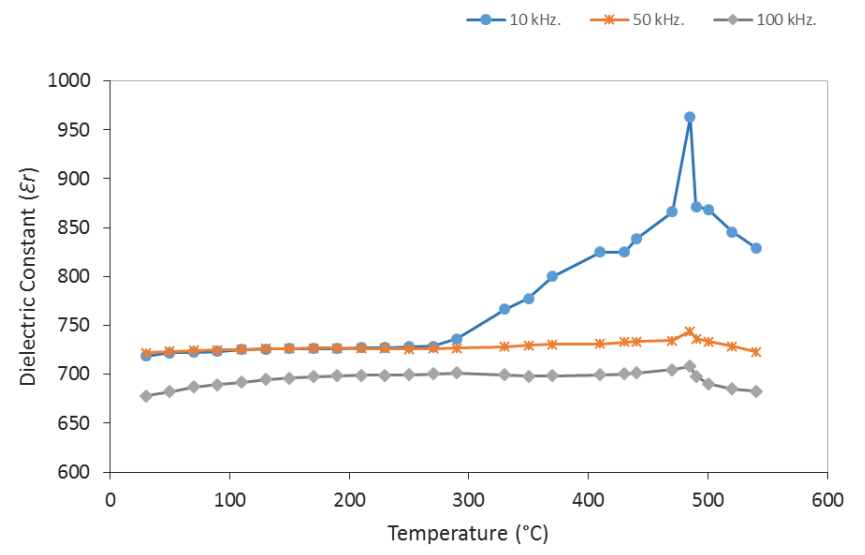

(a)

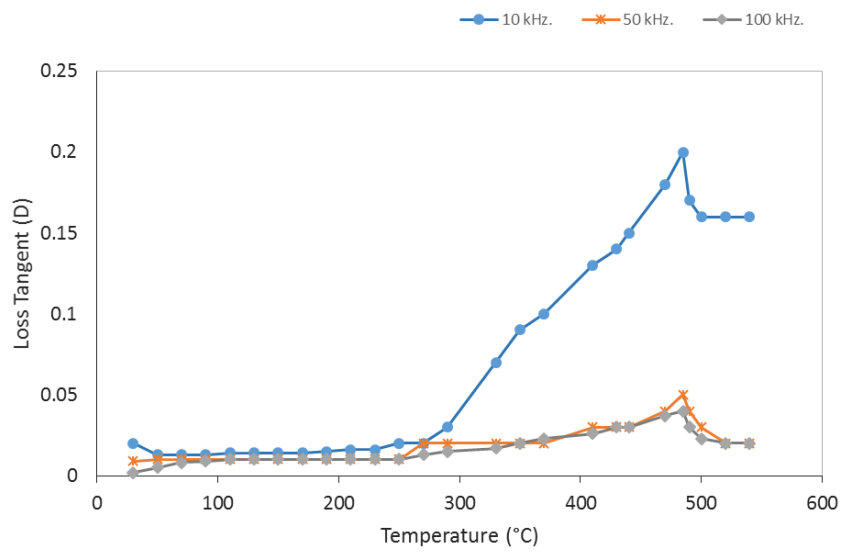

(b)

Fig. 7. The dielectric measurement of $\mathrm{BaTi}_{2} \mathrm{O}_{5}$ ceramics for the sample under the condition $\mathrm{pH}=8$, pressure $=20$ bar, temperature $=208^{\circ} \mathrm{C}$, the reaction time $=60 \mathrm{~h}$, and different frequencies, (a) dielectric constants, (b) loss tangent.

appearing by nanoparticle and nanorode. The higher value produced in the relative permittivity is regarding the small nanosize appearing that ensured the strength of octahedrons within the monoclinic structure and grains distribution.

There is a plateau in the relative permittivity and the loss tangent in the temperature range before $400^{\circ} \mathrm{C}$. It returns to a constant relative permittivity in the range $700-750$ for different frequency, and constant loss tangent at (0.01). Normally, the relative permittivity is related to the amount of polarization included, and then the concentration of electric dipole moments within the structure. It is a function to the ferroelectric strength included and the last is a function of octahedrons including per monoclinic unit cell. Whereas, the constant loss tangent is a function of the energy lost due to temperature increase, then there is no change in the polarization as a function of temperature with different frequencies because fixing the energy lost, or in other word, the concentration of octahedrons within the structure is unchanged. The loss tangent reaches to $0.23,0.05$ and 0.04 at $T_{c}=485^{\circ} \mathrm{C}$ for frequencies 10,50 and $100 \mathrm{kHz}$, as shown in Fig. 7(b), respectively, which was nearly the same for the previous one. The $Q$-factor is $4.35,20$, and 25 which means the material is more applicable at high frequencies 50 and $100 \mathrm{kHz}$ by storing much more energy inside it.

The change in electrical properties might be happening in the solid solution phase with variable Ba:Ti ratio and its composition was affected by temperature dependence on the production of nanostructures in both samples. ${ }^{21}$ The maximum relative permittivity for $\mathrm{BaTi}_{2} \mathrm{O}_{5}$ ceramics were twice in magnitude compared to previous sample. It is smaller than the single crystal value obtained parallel to the polar $b$-axis. The peak of $\left(\varepsilon_{\max }\right)$ at critical temperature $\left(T_{c}\right)$ was much broader for the ceramic than for the single crystals. That is relating to polycrystalline of ceramics, which were not fully dense and porous probably had a major influence on the overall relative ceramic permittivity. ${ }^{21}$ On the other hand, the unique size of nanostructures is suitable for that. In our results, there is like a sharp peak appearing in the value of $\varepsilon_{\max }$, because of a single phase approaching single crystal and that was investigated by the presence of different nanostructures. ${ }^{15,19}$

\section{Conclusion}

There is a pure phase of $\mathrm{BaTi}_{2} \mathrm{O}_{5}$ dielectric ceramic, which was synthesized by hydrothermal method from the starting materials of barium chloride dihydrate and $\mathrm{TiO}_{2}$ powders under the optimum conditions of $\mathrm{pH}$ value, pressure, the temperature and duration time. The resultant powder showed a pure monoclinic phase for two conditions. While they showed a nanoparticle in the range of $57-189 \mathrm{~nm}$ for the first conditions but the next one showed many nanostructures like nanoparticles and nanorode in the size range of 9-31 nm and dimeter $32-37 \mathrm{~nm}$, respectively. The grains were homogeneous in the polycrystalline phase. The relative permittivity is increasing with temperature and reaches to maximum value at Curie point of about $485^{\circ} \mathrm{C}$ at frequencies $(10,50$ and $100 \mathrm{kHz}$ ) for both samples prepared by different parameters. This value of Curie temperature is considering using higher values recorded in comparison with the literature review that means the prepared sample has a high stability in the polarization. The octahedrons with the monoclinic structure have more stability and high strength because of high Curie temperature. The second thing the high pressure and long duration time showed a multiple nanostructure appearing with lowest size. That is more common in preparation of different structures by hydrothermal method.

\section{References}

${ }^{1}$ E. K. Al-Shakarchi, Dielectric properties of a $\mathrm{BaTiO}_{3}$ ceramic prepared by using the freeze drying method, J. Korean Phys. Soc. 57, 245 (2010). 
${ }^{2}$ N. B. Mahmood and E. K. Al-Shakarchi, Three techniques used to produce $\mathrm{BaTiO}_{3}$ fine powder, J. Mod. Phys. 2, 1420 (2011).

${ }^{3}$ N. B. Mahmood, E. K. Al-Shakarchi, B. Elouadi and X. Feaugas, Crystal structure of $\mathrm{Ba}_{x} \mathrm{Sr}_{1-x} \mathrm{TiO}_{3}$ fine powder, J. Mod. Phys. 6, 70 (2015).

${ }^{4}$ Y. Akishige, K. Fukano and H. Shigematus, New ferroelectric $\mathrm{BaTi}_{2} \mathrm{O}_{5}$, Jpn. J. Apple. Phys. 42, L946 (2003).

${ }^{5}$ N. Sareechaa, W. AliShahb, M. Anis-ur-Rehmanc, M. L. Mirzaa and M. S. Awa, Electrical investigations of $\mathrm{BaTiO}_{3}$ ceramics with $\mathrm{Ba} / \mathrm{Ti}$ contents under influence of temperature, J. Solid State Ionics 303, 16 (2017).

${ }^{6}$ Y. Park, A. Grichener, J. Jensen and S. H. Choi, Electrical and optical property of ferroelectric $\mathrm{BaTiO}_{3}$, Proc. of SPIE Photonic West conf., Paper No. 5725-10 (2005).

${ }^{7}$ Z. Shen, X. Wang, B. Luo and L. $\mathrm{Li}, \mathrm{BaTiO}_{3}-\mathrm{BiYbO}_{3}$ perovskite materials for energy storage applications, J. Mater. Chem. A 3, 1 (2015).

${ }^{8}$ T. Akashi, H. Iwata and T. Goto, Preparation of $\mathrm{BaTi}_{2} \mathrm{O}_{5}$ single crystal by a floating zone method, J. Mater. Trans. 44(4), 802 (2003).

${ }^{9}$ J. J. Ritter, R. S. Roth and J. E. Blendell, Alkoxide precursor synthesis and characterization of phases in the barium-titanium oxide system, J. Am. Cera. Soc. 69(2), 155 (1986).

${ }^{10} \mathrm{Y}$. Xu, G. Huang and H. Long, Sol-gel synthesis of $\mathrm{BaTi}_{2} \mathrm{O}_{5}$, J. Mater. Lett. 57, 3570 (2003).

${ }^{11} \mathrm{~L}$. Wang, G. Li and Z. Zhang, Synthesis of $\mathrm{BaTi}_{2} \mathrm{O}_{5}$ nanobelts, J. Mater. Res. Bull. 41, 842 (2006).

${ }^{12} \mathrm{~J}$. Yu and Y. Arai, Anomalous permittivity during crystallization of $\mathrm{BaTi}_{2} \mathrm{O}_{5}$ glass, J. Ferroelectr. 333, 221 (2006).

${ }^{13}$ J. Peng, C. Wang, L. Li, Q. Shen and L. M. Zhang, Synthesis of single-phased $\mathrm{BaTi}_{2} \mathrm{O}_{5}$ powders by arc-melting, J. Adv. Mater. Res. 279, 44 (2011).
${ }^{14}$ J. Peng, C. B. Wang, L. Li, Q. Shen and L. M. Zhang, Preparation and property of $\mathrm{BaTi}_{2} \mathrm{O}_{5}$ ceramics by arc-melting and spark plasma sintering, J. Electroceram. 28, 256 (2012).

${ }^{15}$ J. Li, G. Ba, X. Qi, X. Li, Y. Song and B. Li, Nanocrystalline $\mathrm{BaTi}_{2} \mathrm{O}_{5}$ dielectric ceramic prepared by full crystallization from containerless solidified glass, J. Adv. Ceram. 5(1), 77 (2016).

${ }^{16}$ W. Liu, S. Tsukada and Y. Akishige, Dielectric properties of spark plasma sintered $\mathrm{BaTi}_{2} \mathrm{O}_{5}$ ceramics prepared through sol-gel process, J. Funct. Mater. Lett. 7(4), 14500451 (2014).

${ }^{17}$ N. B. Mahmood and E. K. Al-Shakarchi, Dielectric properties of BNT-xBT prepared by hydrothermal process, J. Adv. Dielect. 7(3), 17500191 (2017).

${ }^{18} \mathrm{~K}$. Byrappa and T. Ohachi, Crystal Growth Technology (Elsevier Inc., 2003).

${ }^{19}$ J. Yu, S. Tang, R. Wang, Y. Shi, B. Nie, L. Zhai, X. Zhang and $\mathrm{Y}$. Du, Synthesis of single-crystalline barium dititanate nanobelts, Crystal Growth Des. 8(5), 1481 (2008).

${ }^{20}$ H. Shigematsu, Y. Akishige, S. Gvasaliya, V. Pomjakushin, S. Lushnikov and S. Kojima, Neutron powder diffraction study of the phase transition in $\mathrm{BaTi}_{2} \mathrm{O}_{5}$, Ferroelectrics 346, 43, (2007).

${ }^{21}$ H. Beltran, B. Gomez, N. Maso, E. Cordoncillo, P. Escribano and A. R. West, Electrical properties of ferroelectric $\mathrm{BaTi}_{2} \mathrm{O}_{5}$ and dielectric $\mathrm{Ba}_{6} \mathrm{Ti}_{17} \mathrm{O}_{40}$ ceramics, J. Appl. Phys. 97, 0841041 (2005).

${ }^{22} \mathrm{~J}$. Xu and Y. Akishiga, Synthesis and dielectric properties of KF-doped $\mathrm{BaTi}_{2} \mathrm{O}_{5}$ ceramics, Ferroelectrics 356, 24 (2007). 